\title{
Traumatic Brain Injury-A Review of Intravenous Fluid Therapy
}

\author{
Armi Pigott and Elke Rudloff* \\ BluePearl Specialty + Emergency Pet Hospital, Glendale, WI, United States
}

This manuscript will review intravenous fluid therapy in traumatic brain injury. Both human and animal literature will be included. Basic treatment recommendations will also be discussed.

Keywords: traumatic brain injury, TBI, fluid therapies, colloid, crystalloid, osmotherapy, mannitol, hypertonic saline

\section{INTRODUCTION}

It is reported that up to $34 \%$ of dogs and cats sustaining blunt force trauma will have head and neck injury. In $10 \%$ with mild head injury and $80 \%$ with severe head injury, intraparenchymal and extra axial hematomas have been detected with advanced imaging (1). Evidence of head trauma is significantly associated with mortality in dogs suffering blunt force trauma (2) and the overall mortality rate is reported to be $24-35 \%(3,4)$. Therapeutic interventions for treating dogs and cats with traumatic brain injury (TBI) are extrapolated from experimental evidence, isolated veterinary reports, human clinical investigations, and anecdotal experience. Confounding injuries, including hemorrhage and additional organ injury, can complicate the decision-making process as well as outcome. Understanding the unique anatomy of the blood brain barrier (BBB) and autoregulation of blood flow, and how they become affected by trauma can provide the clinician with a foundation from which to write a fluid prescription for the patient with TBI.

\section{NORMAL BLOOD BRAIN BARRIER}

${ }^{*}$ Correspondence: Elke Rudloff aecerdvm@aol.com

Specialty section:

This article was submitted to Comparative and Clinical Medicine,

a section of the journal

Frontiers in Veterinary Science

Received: 18 December 2020 Accepted: 09 June 2021 Published: 09 July 2021

Citation:

Pigott $A$ and Rudloff E (2021)

Traumatic Brain Injury $-A$ Review of Intravenous Fluid Therapy.

Front. Vet. Sci. 8:643800

doi: 10.3389/fvets.2021.643800

The brain is highly dependent on a continuous and regulated supply of oxygenated blood traveling through a highly regulated conduit lined by the BBB. The BBB is a physical, transport, and metabolic wall that separates the contents of the blood vessels from the brain interstitium and cells. The endothelial cells lining the vessels of the brain are fenestrated by transmembrane proteins (occludin and claudins or junctional adhesion molecules) anchored to the cytoplasmic surface by scaffolding proteins (zonula occludens) that physically control particle movement through the intercellular clefts and paracellular pathways (5). The capillary membrane is incompletely swathed by pericytes, and together they are encased by a basement membrane constructed by extracellular matrix molecules. Astrocytes extend cellular processes that encase the vessel, neuronal synapses, and nodes of Ranvier, which together make the neurovascular unit. Specific transport mechanisms mediate solute movement across the BBB, and enzymes metabolizing molecules in transit act as a metabolic barrier.

An intact BBB acts as a solute exchange barrier between circulating blood and the brain environment, and functions to allow nutrient delivery and waste removal while limiting entry of immune cells, pathogens, and toxins. The intact $\mathrm{BBB}$ is permeable to oxygen, water, and small lipid soluble molecules. 


\section{BLOOD BRAIN BARRIER DISRUPTION IN TRAUMATIC BRAIN INJURY}

Dysfunction of the BBB precipitates several key events (6). Paracellular transport of restricted components, in particular neutrophils, increases with the loss of tight junction proteins, and transcytosis of larger molecules such as serum proteins increases across the endothelial cell. This establishes an inflammatory response and an increase in interstitial fluid resulting in vasogenic edema. In addition, activation of cellular membrane ion channels results in intracellular water accumulation and cytotoxic edema, culminating in an increase in brain volume. Following a traumatic event, brain edema will be heterogenous, and alterations in blood flow and oxygen delivery will depend on the severity and region(s) affected.

Since the brain parenchyma is protected within a nondistensible calvarium, an increase in brain volume from edema will increase ICP and reduce CPP in a non-linear manner, resulting in brain ischemia, the single most important secondary insult that can occur following TBI. Therapeutic goals in mitigating the reduction in CPP include optimizing systemic $\mathrm{MAP}$, and, when necessary, decreasing intracranial volume with osmotherapy.

\section{CPP AND OPTIMIZING MAP}

Blood flow to the normal brain is minimally affected with a MAP between $50-150 \mathrm{mmHg}$ due to autoregulatory mechanisms. A traumatic insult to the brain is followed by disruption of the $\mathrm{BBB}$ and cellular injury, and infiltration of inflammatory cells. Their release of cytokines induces nitric oxide production resulting in vasodilation and failure of cerebral pressure autoregulation. Cerebral blood flow in the injured region then becomes dependent on CPP. Systemic hypotension becomes a major contributor to a reduction in CPP, and therefore must be corrected and prevented. Causes of hypotension in patients with TBI can include hemorrhage, third-space fluid losses, and vasoplegia. In addition, polytrauma is common in patients with TBI, and multiorgan damage resulting in hypoxemia, hypovolemia, and systemic inflammation can contribute to the secondary insult to injured brain tissue and complicate the approach to treatment.

Intravenous (IV) fluid therapy is the mainstay of fluid resuscitation from hypovolemia regardless of the extent of trauma. Fluid types include a balanced, buffered, isotonic crystalloid (e.g., Plasma-Lyte, Normosol-R), an isotonic crystalloid with a higher sodium concentration ( $0.9 \%$ sodium chloride), hypertonic saline (HTS 3-7.5\%), and/or a synthetic or natural colloid. It can be argued that hyponatremic fluids [e.g., lactated Ringer's solution (LRS)] should be avoided unless the patient is hyponatremic, since they might produce an increased osmolar gap that could favor brain water accumulation (7). A discussion on studies relevant to fluid therapy in animals and people with TBI follows.

\section{RESUSCITATION FLUIDS IN PATIENTS WITH TRAUMATIC BRAIN INJURY AND HEMORRHAGIC SHOCK}

Widely recognized for their guidelines for treating TBI, the Brain Trauma Foundation (BTF) (8) and the Lund Concept (9) have published controversial recommendations for the treatment of TBI. The BTF interventions are based on a set of evidencebased recommendations gleaned from a literature review of published studies, and the BTF guidelines do not make any recommendations about the use of any specific fluid type. The Lund Concept describes non-individualized, pre-emptive, ICP-regulating and perfusion-targeted therapy for manipulating transcapillary fluid dynamics using albumin (in addition to vasodilators and avoiding the use of vasopressors), but lacks strong evidence supporting the protocol $(10,11)$. There are no clinical trials evaluating any fluid type for resuscitation from hemorrhagic shock in veterinary patients with TBI. There are however dog, cat, pig, rat, and mouse models of hemorrhagic shock and TBI that have been used in the laboratory setting, as well as human clinical trials, attempting to identify the optimal fluid for resuscitation.

\section{Isotonic Crystalloids}

Isotonic crystalloid solutions have been evaluated in the laboratory and human clinical trial setting. They are often the first-line therapy in the pre-hospital environment. However, crystalloids lack any pro-survival properties (12) and there is no survival benefit associated with aggressive crystalloid resuscitation in bleeding patients $(13,14)$. Modern damage control resuscitation guidelines for hemorrhaging patients recommend avoidance of crystalloid fluids in favor of early initiation of a 1:1:1 ratio-based transfusion strategy using packed red blood cells, plasma, and platelets (15). This strategy may mitigate hemodilution, hemostatic derangements, brain edema, and inflammation associated with large volume crystalloid infusion and worsening of uncontrolled hemorrhage (9, 15-17). In a pig model of TBI and uncontrolled hemorrhage, $100 \%$ of pigs died in less than one hour when aggressively resuscitated with isotonic crystalloid solution to a MAP of $80 \mathrm{mmHg}$, while $50 \%$ of pigs that were allowed to remain hypotensive with no resuscitation for one hour survived and went on to have cerebral blood flow return to normal in the second hour following surgical hemostasis and resuscitation with shed blood (18). Hypotensive resuscitation during damage control resuscitation is contraindicated in people with TBI, where resuscitation to a systolic BP of $90-110 \mathrm{mmHg}$ with limited crystalloid infusion is recommended (15).

When compared to synthetic colloids, animals resuscitated with $0.9 \%$ sodium chloride or LRS required larger volumes of fluid to reach and maintain hemodynamic endpoints, developed progressive acidosis, and were volume-dependent to maintain 
MAP and CPP $(19,20)$. Other animal model studies found that resuscitation from hemorrhagic shock with isotonic crystalloid solutions was associated with lower CPP, higher ICP, lower MAP, higher glutamate-mediated excitotoxic secondary brain injury and increased mitochondrial dysfunction, lower brain tissue oxygenation, more brain edema, larger brain lesion size, upregulation of inflammatory pathway genes, increased activation of coagulation, anticoagulation, and endothelial systems, greater degree of neurologic impairment, and markedly slower rate of neurologic recovery when compared to plasma products, regardless of the type of TBI model studied $(17,19-28)$.

\section{Synthetic Colloids}

Synthetic colloids, in particular hydroxyethyl starch (HES), are readily available, but their use in critically ill human patients is limited primarily due to increased rates of acute kidney injury and need for renal replacement therapy following administration (29). There are relatively few studies evaluating synthetic colloids in TBI patients, and all but one used experimental animal models. Formation of cerebral edema was greater in a rat model of mild to moderate TBI resuscitated with isovolemic hemodilution using 0.9 or $0.45 \%$ sodium chloride compared to whole blood or $6 \%$ HES 670/0.75, possibly from a reduction in colloid osmotic pressure (COP) (30). In pig models of TBI and hemorrhage testing various crystalloid and colloid infusion, resuscitation with 6\% HES 670/0.75 in LRS required less total volume to achieve hemodynamic endpoints, resulted in a steady improvement in base excess and a CPP $>70 \mathrm{mmHg}$ by $270 \mathrm{~min}$ post-injury and resuscitation $(19,20)$. Animals were hypercoagulable in both the LRS and HES groups based on thromboelastographic testing, and there was no difference in transfusion requirement, time to wean from the ventilator, or mortality compared to animals resuscitated with $0.9 \%$ sodium chloride. In another pig model of TBI with polytrauma and hemorrhage, $0.9 \%$ sodium chloride, $6 \%$ HES 670/0.75, and fresh frozen plasma (FFP) were compared as resuscitation fluids (24). HES reduced edema and lesion size compared to $0.9 \%$ sodium chloride, but not as effectively as FFP.

The only identified clinical study specifically evaluating synthetic colloids in patients with TBI was a single-center retrospective cohort study of 171 people with severe TBI (31). In this cohort $78 \%$ of patients received 6\% HES 200/0.5 during hospitalization. There was no association with mortality, change in serum creatinine, or establishment of renal injury. The Crystalloid vs. Hydroxyethyl Starch Trial (CHEST) evaluated $6 \%$ HES 130/0.4 and pre-specified a TBI subgroup analysis (32). However, only a small number of patients with TBI were recruited preventing any reliable conclusion $(32,33)$.

\section{Natural Colloids}

The rationale for using natural colloids as a resuscitation fluid is to avoid or reduce the amount of isotonic crystalloid fluid infused thereby avoiding the complications such as increased brain edema $(9,34)$, and to avoid use of the synthetic colloids, which, in people, is associated with significant adverse outcomes in many critically ill populations (29). Albumin as a resuscitation fluid during TBI has been evaluated in animal models and human clinical trials with conflicting results. The most notable study was the SAFE (Saline vs. Albumin Fluid Evaluation) trial and subsequent post-hoc analysis $(34,35)$. The SAFE trial was a randomized controlled trial comparing $4 \%$ albumin to $0.9 \%$ sodium chloride for resuscitation from hemorrhagic shock. A secondary analysis of the subset of patients with hemorrhagic shock and TBI found the patients resuscitated with $4 \%$ albumin had higher mortality rate than the subset resuscitated with $0.9 \%$ saline $(34,36)$. This was in contrast to smaller single center and animal studies that suggested a beneficial effect of albumin $(37,38)$. The mechanism for this outcome cannot be determined from the SAFE trial because the study was not designed to answer this question $(9,34,36)$.

Resuscitation with hypoosmolar solutions (including 4\% albumin) has been associated with increased brain edema (36). These authors postulate that this may be the reason for increased mortality associated with $4 \%$ albumin resuscitation, and that the osmolality of an infusion solution rather than the COP may be more important in the pathogenesis of cerebral edema formation associated with resuscitation fluids $(9,36)$. Other authors suggest that with a loss of BBB integrity, any colloid might leak into the brain and pull water with it (39). The Lund Concept recommendations continue to support the use of $4 \%$ albumin (9) in spite of the evidence of harm $(34,36)$.

There is increasing evidence in the general trauma population that ratio-based resuscitation with high ratios of FFP to packed red blood cells confers a survival advantage to patients requiring massive transfusion (40). This may be due to avoidance of the complications associated with large-volume crystalloid resuscitation $(41,42)$. There is also evidence that FFP exerts a protective effect on the endothelium and endothelial glycocalyx layer (22, 41-43), and may protect or help to heal the BBB when administered early to patients with TBI $(22,42,43)$. Plasma products have been evaluated as a resuscitation fluid in animal models and human patients with TBI. Fresh frozen plasma, lyophilized plasma, and spray-dried plasma perform similarly when compared to one another $(23,28,43,44)$, and consistently outperform resuscitation with crystalloid or colloid solutions $(21-23,26-28,36,42,44-49)$.

In animal models of TBI, use of plasma products consistently resulted in favorable responses when compared to resuscitation with isotonic crystalloids $(21-23,25-28,40-45,47)$ or HES (26). Resuscitation from hemorrhagic shock with plasma products was associated with improved CPP, higher MAP, improved brain tissue oxygenation, and reduced brain edema and lesion size (21$23,26)$. In addition, administration of plasma products resulted in diminished glutamate-mediated excitotoxic secondary brain injury and reduced mitochondrial dysfunction $(21,26)$, downregulation of inflammatory pathway genes and expression of gene clusters mapping to increased metabolic and platelet signaling (26), a lesser degree of neurologic impairment, and markedly faster rate of neurologic recovery (28).

The results of human clinical data surrounding the use of plasma products to treat patients with TBI are mixed and complicated by small sample size and differences in protocols and study population. There are two single center, prospective, randomized trials evaluating the early empirical use of FFP in patients with severe closed head injury: one 
with 63 patients receiving $5 \mathrm{ml} / \mathrm{kg}$ (50) and one with 90 patients receiving $10-15 \mathrm{ml} / \mathrm{kg}$ (51). Fresh frozen plasma or an equal volume of $0.9 \%$ sodium chloride was administered over $3-4 \mathrm{~h}$ following initial hemodynamic stabilization and CT scan. The fluid types and volumes used for initial stabilization are poorly described but may have included blood products, crystalloids, and/or colloids. In both studies, early empirical use of FFP was associated with an increase in delayed traumatic intracerebral hematoma formation. The study by Zhang (50) showed increased rate of blood transfusion and coagulopathy, but no mortality difference in patients receiving FFP, whereas the study by Etemadrezaie (51) showed increased mortality but no difference between groups for rate of coagulopathy (there was no comment on transfusion requirements).

Gruen (46) et al. reported the secondary analysis of a predefined subgroup of patients with TBI from the PAMPer trial. The PAMPer trial (52) was a multi-center, clusterrandomized, phase-3 superiority clinical trial comparing plasma administration to standard-care resuscitation in severely injured patients during air-medical transport, and the primary outcome was mortality at 30 days. The study enrolled patients transported from an outside referral emergency department and directly from the scene of the accident. Patients were randomized to receive plasma vs. no plasma in addition to standard care. From that cohort, a subset of patients with TBI were included in the secondary analysis. Among patients with TBI, the group receiving resuscitation with plasma during air transport had improved 30-day survival compared to those that did not. They also received less crystalloid fluid, vasopressors, and packed red blood cells in the first $24 \mathrm{~h}$, had lower international normalized ratios, lower $24 \mathrm{~h}$ mortality, and lower 30-day mortality. The plasma group also had higher incidence of multiple organ failure, longer ICU stay, and longer hospital length of stay. Plasma treatment was associated with the greatest survival benefit in the sickest/most severely injured of these patients. Additionally, transport origin (scene of accident vs. hospital transfer) was used as a proxy for time-to-plasma resuscitation. When grouped by transport origin, patients transported from the scene of the accident who received plasma had lower 30-day mortality than those who did not receive plasma, while there was no difference between patients receiving plasma vs. no plasma when transported from a referral emergency department, suggesting that minimizing time from injury to administration may be important (46).

Retrospective studies also suggest patients with TBI benefit from early resuscitation with plasma (40, 53). Unlike the two single-center prospective trials already discussed, patients in these retrospective trials received plasma as part of the initial resuscitation. Jokar (53) et al. report on 1:1:1 (plasma:pRBC:platelet) ratio-basedresuscitation vs. non-ratio-based resuscitation in trauma patients with isolated TBI and intracranial hemorrhage. Patients receiving ratio-based resuscitation received more plasma and no crystalloid compared to non-ratio-based resuscitation, had significantly lower mortality compared to those who did not, and crystalloid administration was associated with increased odds of death. Additionally, there was no difference in progression of intracranial hemorrhage or rate of neurosurgical intervention between groups (53).

Chang (39) et al. evaluated early plasma transfusion during initial resuscitation in patients with isolated TBI without polytrauma and intracranial hemorrhage at a single center. Evaluation of the full cohort showed no difference in baseline characteristics or survival between patients receiving plasma and those who did not. Patients were then sub-grouped based on the dominant brain lesion: extradural hematoma, subdural hematoma, intraparenchymal contusion, subarachnoid hemorrhage, or multifocal intracranial hemorrhage. There were significant differences in age, mechanism of injury, hypoperfusion, injury severity, early plasma transfusion, and survival among the different subgroups. In the subgroup with multifocal intracranial hemorrhage early plasma transfusion was associated with improved survival. Compared to patients with extradural hematoma, subdural hematoma, intraparenchymal contusion, or subarachnoid hemorrhage, these patients were more likely to present with markers of more severe injury: severe TBI, hypotension, hypoperfusion, more severe injuries, and coagulopathy. Twenty-five percent of these patients received early plasma transfusion which was associated with improved in-hospital survival. Early plasma transfusion was not associated with improved survival in any of the other subgroups (39). It is difficult to make direct comparisons between any of these studies due to the significant differences in populations, protocols, and study design.

\section{Hyperosmolar Fluids During Resuscitation}

An intact $\mathrm{BBB}$ is required for a predictable response to osmolar gaps to occur (54-56). Following a significant TBI, cerebral edema may be reduced by a hyperosmolar fluid infusion (54, 57-59). Use of hyperosmolar solutions during initial resuscitation is not discussed in either of the human guidelines $(8,9)$ although they are evaluated in the experimental and human clinical literature. When used empirically in the prehospital setting as a low-volume resuscitation fluid, 7.5\% HTS is well-tolerated but does not confer a survival benefit compared to isotonic crystalloid resuscitation $(33,60,61)$. However, in patients with intracranial hypertension both HTS (3-23.4\%) and mannitol effectively lower ICP $(33,62)$. In two experimental dog models of TBI and hemorrhage the animals were resuscitated with either $3 \%$ HTS $(8 \mathrm{~mL} / \mathrm{kg})$ or LRS (16 $\mathrm{mL} / \mathrm{kg})(63,64)$. Animals resuscitated with HTS had higher CPP, lower ICP, higher serum sodium and osmolarity, less cerebral edema, and faster return of pupil responses compared to animals resuscitated with LRS. When animals were further resuscitated by returning their shed blood to maintain MAP $>70 \mathrm{mmHg}$ there was no difference in total volume infused between groups (64). In a rat model of TBI and hemorrhage, HTS (7.5\%) resuscitation was associated with improved longterm neuronal survival as well as faster and more complete 
behavioral recovery compared to $0.9 \%$ sodium chloride or no resuscitation (65).

\section{FLUID RESUSCITATION TECHNIQUE}

The fluid administration and shock management technique might also matter, particularly in patients with uncontrolled hemorrhage. Current BTF (8) and damage control resuscitation guidelines (15) recommend strongly against hypotensive resuscitation in favor of resuscitation to a systolic BP 90$110 \mathrm{mmHg}$. There is evidence that even transient episodes of hypotension lead to irreversible secondary brain damage in a time- and dose-dependent manner (66-68). However, experimental data suggests normotensive resuscitation prior to hemorrhage control may not be the optimal strategy. Vrettos (18) et al. compared aggressive crystalloid resuscitation to no initial resuscitation in a pig model of TBI with hemorrhage. TBI was induced in anesthetized pigs followed by abdominal hemorrhage to a MAP of $30 \mathrm{mmHg}$. After $6 \mathrm{~min}$ of hypotension the animals were randomized and either resuscitated to a systolic BP of $80 \mathrm{mmHg}$ with LRS or allowed to remain hypotensive. Animals surviving to $1 \mathrm{~h}$ post-injury then underwent surgical hemostasis and $1 \mathrm{~h}$ of resuscitation with shed blood. All animals in the early aggressive fluid resuscitation group died of exsanguination and hemorrhagic shock in less than an hour, none surviving to undergo surgical hemostasis and further resuscitation. Half of the animals in the hypotensive group survived to receive surgery and resuscitation. In the survivors, MAP, cardiac output, cerebral blood flow and oxygen measurements were restored to pre-hemorrhage levels. There was no evaluation of brain lesion size or any functional outcome in these animals. The authors suggest that while hypotension is suboptimal in TBI, bleeding to death leaves no chance of survival, and other resuscitation strategies need to be investigated.

In another pig TBI and uncontrolled abdominal hemorrhage model, resuscitating pigs with vasopressin plus 6\% HES 670/0.75 in LRS increased blood pressure but failed to improve cerebral blood flow and increased abdominal hemorrhage volume compared to resuscitation with HES only and to no resuscitation (66). A third pig TBI and hemorrhage model compared FFP and $0.9 \%$ sodium chloride administered as either a large rapid bolus or slower stepwise resuscitation (27). Pigs underwent TBI and $40 \%$ blood loss, were kept hypotensive for $2 \mathrm{~h}$, then resuscitated with FFP or $0.9 \%$ sodium chloride. The FFP group received the shed blood volume back as either a fast bolus $(50 \mathrm{ml} / \mathrm{min})$ or stepwise infusion starting at $2 \mathrm{~mL} / \mathrm{min}$ and gradually increasing to $50 \mathrm{~mL} / \mathrm{min}$. The $0.9 \%$ sodium chloride group received $3 \mathrm{x}$ the shed blood volume either as a bolus at $165 \mathrm{~mL} / \mathrm{min}$ or starting at $6 \mathrm{ml} / \mathrm{min}$ and gradually increasing to $165 \mathrm{~mL} / \mathrm{min}$. Animals were euthanized and tissue harvested after $6 \mathrm{~h}$. Bolus FFP or $0.9 \%$ sodium chloride resulted in greater brain swelling but similar lesion size to stepwise FFP or $0.9 \%$ sodium chloride, suggesting that stepwise infusion is superior to rapid bolus. In addition, $0.9 \%$ sodium chloride infusion resulted in more swelling and a larger brain lesion when compared to both FFP infusion types.

\section{MANAGING ELEVATED ICP WITH OSMOTHERAPY}

Osmotherapy is the infusion of a hyperosmolar fluid with the intention of producing an osmolar gap and transferring brain parenchymal fluid into the vessels to be excreted in the urine. This reduces blood viscosity, which improves rheology resulting in constriction of pial arterioles (68-70). A direct effect at the site of injury may not be realized should blood flow to the site of injury be limited, or the BBB be disrupted. However, in regions where the $\mathrm{BBB}$ is intact, the osmolar gap may remove water that has accumulated in the brain cell and interstitium, and reduce ICP. The most common fluids used for osmotherapy include mannitol (20 and 25\%) and HTS (3, 7.5, 24\%). Their differences are summarized in Table 1. A key difference between the two fluids is that HTS can be used for dual purpose in treating hypovolemic shock as well as reduce cerebral edema. There is no strong evidence to support any recommendation for the use of osmotherapy for the treatment of traumatic intracranial hypertension or using one over another, and a summary of the evidence follows.

A single clinical veterinary study evaluating the effect of isosmotic mannitol and 3\% HTS in two cats and one dog was identified (71). The animals were presented to a veterinary teaching hospital with naturally occurring head trauma, received immediate cardiovascular resuscitation with LRS, pain control with fentanyl, and antibiotic coverage with cefazolin when indicated. A brain MRI was performed within $12 \mathrm{~h}$ of presentation and as soon as the animals were considered stable. Animals suspected to have elevated ICP were instrumented for direct ICP monitoring immediately following imaging and randomized to receive either $18 \%$ mannitol or $3 \%$ HTS. ICP and $\mathrm{CPP}$ were recorded before and at five timepoints during the 120 min post-treatment. Patient one received 3\% HTS and had no response to treatment. Patient two received 3\% HTS resulting in an approximately $40 \%$ decrease in ICP and $15 \%$ increase in CPP. The ICP remained lower than baseline however the patient became hypotensive requiring further isotonic fluid resuscitation and dopamine to raise the MAP. This period of hypotension resulted in a decreased CPP, and the patient's response to $3 \%$ HTS was therefore classified as transient. The third patient received $18 \%$ mannitol. Initially the ICP decreased by $19 \%$ and the CPP returned to normal, however there was a rebound increase in ICP that was higher than pre-treatment values, and the CPP decreased again before gradually returning to normal over the 120-min monitoring period.

Numerous reviews and meta-analyses evaluate HTS and mannitol against various agents in the human clinical literature $(33,62,72-82)$. In summary, the studies are heterogenous in population, dose, concentration and rate of fluid administered, therapeutic targets, and outcomes of interest. Therefore, the systematic reviews can only draw limited and general conclusions. The available evidence suggests that both mannitol 
TABLE 1 | Characteristics of Mannitol and Hypertonic Saline.

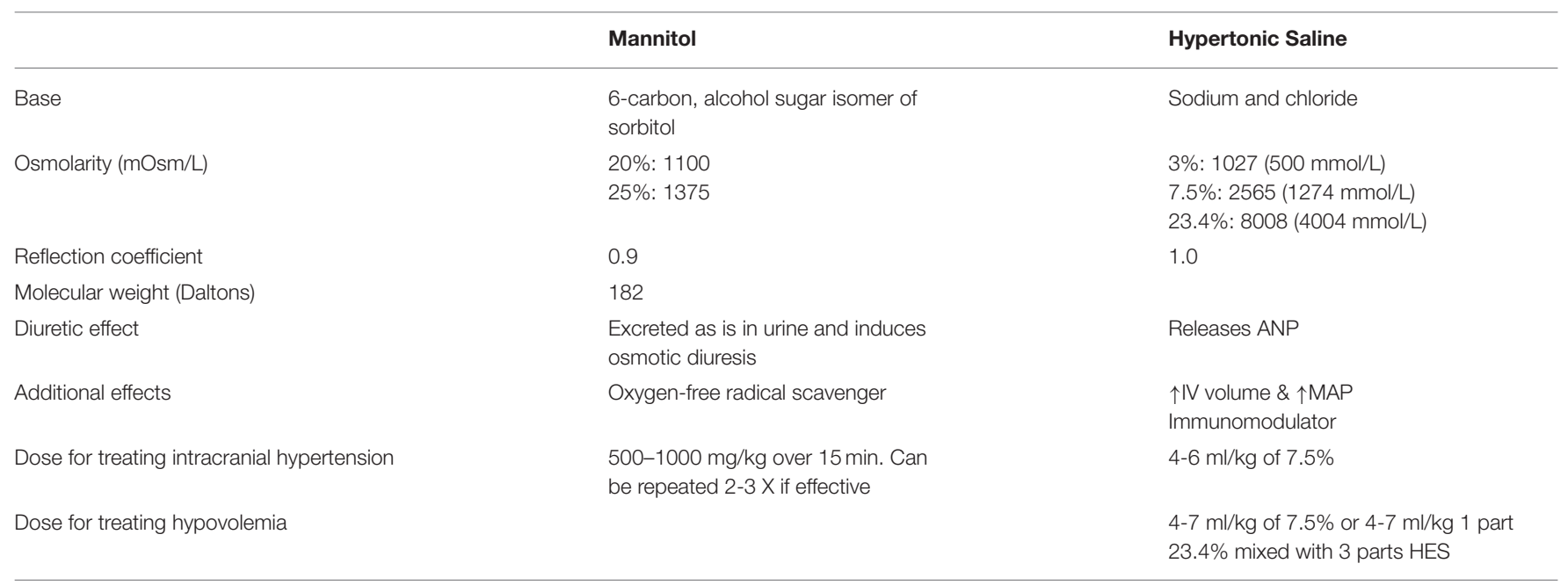

and HTS effectively lower ICP, but there is not enough evidence to suggest one fluid is superior, although a few studies suggest HTS may have slightly fewer treatment failures in patients with refractory intracranial hypertension compared to mannitol $(62,73-76,78,83,84)$. Additionally, HTS avoids diuresis and increases cardiac preload, favorably impacting cerebral perfusion $(33,79)$. Mannitol is associated with a well-documented rebound phenomenon in patients with intracranial hemorrhage and brain tumors, occurring in about $12 \%$ of patients (85-89). A rebound phenomenon was defined in a Cochrane review by Chen (76) et al. as intracranial pressure rising above its original level after hyperosmolar therapy.' However, the rebound phenomenon occurring in patients with TBI is only mentioned in passing in a single study included in the Cochrane review (76) and in the veterinary pilot study (71). Despite effective reduction of ICP, neither HTS nor mannitol has clinical evidence supporting improved survival or long-term neurologic outcome $(33,75,81)$.

The optimal dose has not been determined for either mannitol or HTS. There is some evidence that higher doses of mannitol $(\sim 1.0-1.5 \mathrm{~g} / \mathrm{kg})$ might be associated with greater reduction of ICP and less rebound phenomenon compared to lower doses of mannitol, although the data surrounding the dose-relationship with rebound phenomenon is conflicting (80, 90-93). A specific, evidence-based dosing strategy for HTS cannot be determined at this time due to insufficient evidence and profound heterogeneity among the various studies. In the veterinary clinical study (71) noted previously, the 2 cats received $5.3 \mathrm{ml} / \mathrm{kg}$ of $3 \%$ HTS IV over $5 \mathrm{~min}$. One had no response to therapy and the other had an approximately $40 \%$ decrease in ICP. The Neurocritical Care Society has published guidelines for acute treatment of cerebral edema in human neurocritical care patients with TBI and recommends symptom-based bolus dosing over sodium-targetbased dosing (94).

Continuous infusion of HTS in patients with various pathologies has been evaluated in a small single center trial and was compared in a pooled analysis against intermittent bolus therapy from two other trials (95). The hazards ratio for survival showed a 90-day functional outcome with continuous infusion to be significantly greater compared to bolus therapy. There were no significant adverse effects observed with HTS continuous infusion $(96,97)$. This is in contrast to pediatric patients, where sustained hypernatremia is associated with thrombocytopenia, kidney failure, neutropenia, and ARDS (97101). The recently published COBI (Continuous hyperosmolar therapy (20\% HTS) in Brain-Injured patients) trial compared functional outcome at 6 months between standard care alone and continuous therapy with $20 \%$ HTS in 370 adults (102). All patients received recommended interventions based on the most recent BTF guidelines. The treatment group received a $1 \mathrm{~h}$ bolus infusion adjusted to their measured serum sodium level within $24 \mathrm{~h}$ of trauma, which was immediately followed by a $0.5-1 \mathrm{~g} / \mathrm{kg} / \mathrm{h}$ continuous infusion of saline. Serum sodium levels were monitored, and the infusion concentration adjusted to prevent an elevation in serum sodium $>155 \mathrm{mmol} / \mathrm{L}$ for a minimum treatment period of $48 \mathrm{~h}$ and only while intracranial hypertension remained a risk. The infusion was stopped once $12 \mathrm{~h}$ had passed following the suspension of all specific therapies for intracranial hypertension. Although the study was underpowered to detect a clinically important difference, the authors concluded that in patients with moderate to severe TBI, there was no significant difference in neurological status between the treatment and control group.

\section{ADDITIONAL CONSIDERATIONS WITH HTS AND MANNITOL}

Several local and systemic pathophysiological consequences contribute to secondary injury of the brain which may be mitigated by HTS and/or mannitol. Hypovolemia, hypotension, cerebral vasospasm, and altered blood flow result in activation of systemic inflammation and hypoxemia. In the brain, cerebral leukocytes congregate in injured areas and initiate vasodilation and peroxidase/protease-mediated 


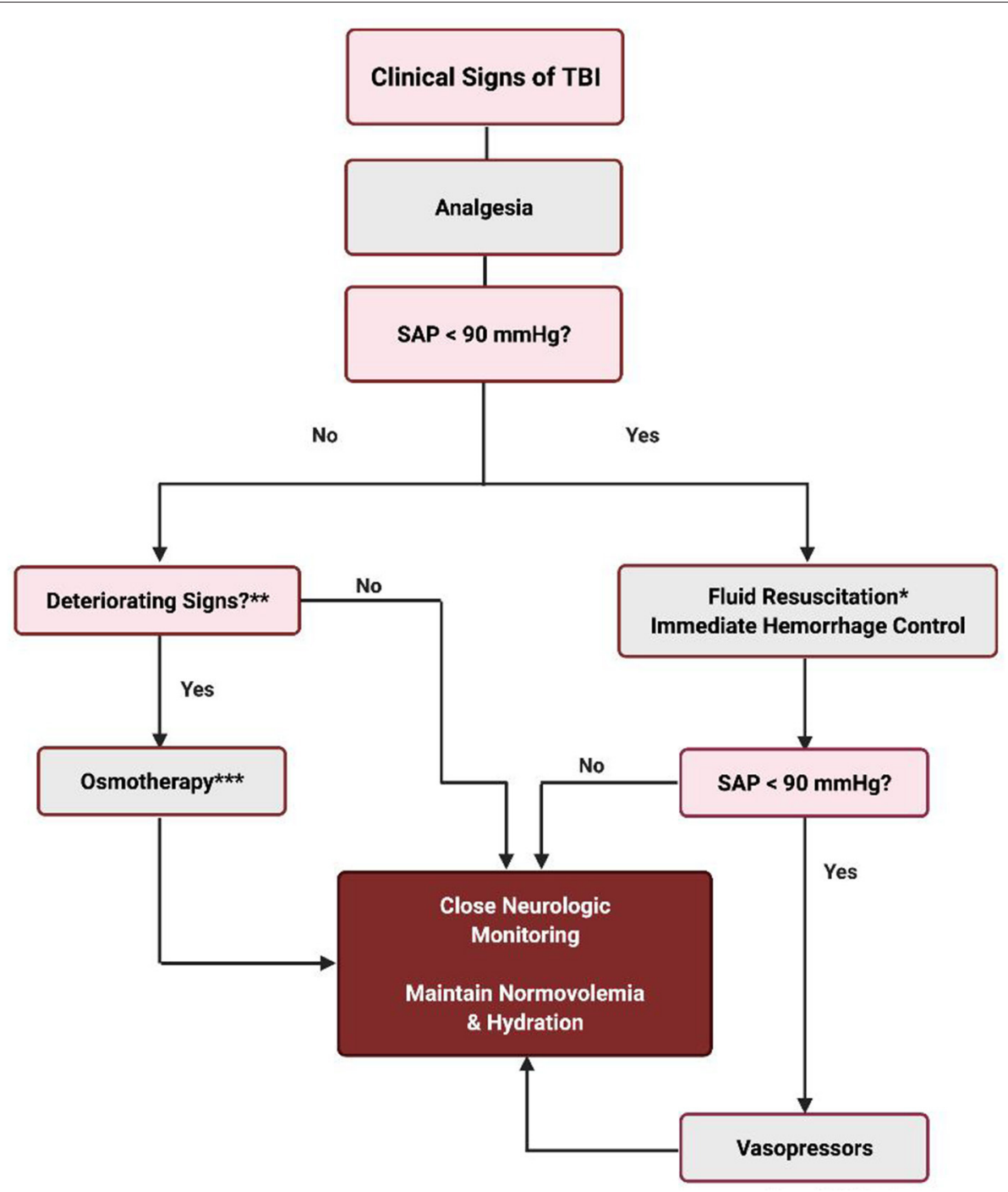

FIGURE 1 | Fluid therapy for the TBI patient. *Fluid resuscitation techniques can be any one of the following or a combination thereof: (1) 10-20 ml/kg crystalloids (Plasma Lyte or Normosol-R) IV rapid infusion up to $60-90 \mathrm{ml} / \mathrm{kg}$. (2) 5-10 ml/kg 6\% HES (tetrastarch) IV rapid infusion up to $40-50 \mathrm{ml} / \mathrm{kg}$. (3) $5-10 \mathrm{ml} / \mathrm{kg} \mathrm{plasma}$ rapid infusion IV up to 20-30 ml/kg. (4) 3-4 ml/kg 7\% HTS IV over 10-15 min. (5) whole blood or pRBC, if indicated. *A Altered level of consciousness with or without bilateral or unilateral miotic pupils; unresponsive mid range pupil(s) or mydriasis; loss of the oculocephalic reflex; bradycardia with hypertension (Cushing reflex); posturing (opisthotonus, decerebellate, decerebrate); alteration of the respiratory pattern. ${ }^{\star \star \star} 1 \mathrm{~g} / \mathrm{kg}$ mannitol IV up to 3 doses q60-90 min OR 3-4 ml/kg 7\% HTS IV.

cell death $(101,103)$. Dysfunction of cell-mediated immunity can occur and may be moderated by HTS (104-107).

Hypoxemia results in the depletion of ATP, cellular membrane ion pump malfunction, intracellular sodium accumulation and endothelial cell swelling. This can narrow the vascular lumen causing red blood cells to pass through vessels with more difficulty, and rupture or cause premature apoptosis of neuronal cells. In addition, brain injury can induce extensive neuronal depolarization which decreases extracellular sodium reversing the direction of the Na-glutamate cotransporter, causing an increase in extracellular glutamate, compounding neurotoxicity (107-110). Using HTS during resuscitation improves alveolar gas exchange by reducing extravascular lung volume, reverses endothelial and red blood cell swelling improving blood flow and oxygen delivery and restores extracellular sodium and cellular action potential, moderating glutamate toxicity in the brain (111-116).

During reperfusion of hypoxemic tissue, the production of radical oxygen species can propagate tissue injury. Mannitol may limit the secondary oxidative injury in the brain by scavenging radical oxygen species (117).

Hypotension caused by a decrease in systemic vascular resistance and/or a vagal-mediated reflex after the rapid administration of HTS has been reported to occur in humans, dogs, and rabbits (118-120). This appears to be transient as it is followed by an increase in MAP and myocardial contractility. 


\section{SUGGESTED THERAPEUTIC APPROACH}

It is clear from the information available that therapeutic recommendations for fluid therapy in the dog or cat with TBI continue to remain the clinician's choice. Maximizing CPP by correcting systemic hypotension is a cornerstone to management of TBI, although this has to be done carefully when also treating severe hemorrhage resulting from polytrauma. Hypovolemia is treated with isotonic crystalloids, hypertonic saline, and/or colloids. A decline in neurological status in the non-hypotensive patient warrants osmotherapy. The authors approach to fluid resuscitation of the small animal patient with TBI is outlined in Figure 1.

\section{ON THE HORIZON}

Various fluid additives and novel molecules are being investigated to identify the optimal resuscitation fluid for patients with TBI. One combination that stands out is HTS containing adenosine, lidocaine, and magnesium. This combination appears to play a protective role in a variety of life-threatening conditions in animal models of sepsis (121-124), non-compressible hemorrhagic shock (125-127), and TBI from non-compressible hemorrhage (128). Interestingly, the drugs do not confer benefit when used individually, and magnesium sulfate alone might increase mortality in humans with TBI (129). LRS with added drag-reducing molecules has been evaluated in a rat model, and appears to improve cerebral microcirculation, increase brain tissue oxygenation, and reduce neuron loss, despite lower mean arterial pressure (130).

Modified hemoglobin-based oxygen carriers (HBOCs) that have reduced nitric oxide scavenging and oxygen-free radical generation are being evaluated as resuscitation fluids in animal models of TBI and hemorrhagic shock (131-133). Polynitroxylated-pegylated hemoglobin (PNPH) is a novel HBOC bovine-origin carboxyhemoglobin with covalently labeled nitroxide moieties being evaluated for use as a small-volume resuscitation fluid (132-134). The polynitroxylation of the hemoglobin molecule has antioxidant properties and prevents nitric oxide scavenging, while the polyethylene glycol side chains create a "hydrating shell" that has a strong oncotic effect useful

\section{REFERENCES}

1. Platt SR, Radaelli ST, McDonnell JJ. Computed tomography after mild head trauma in dogs. Vet Rec. (2002) 151:243. doi: 10.1136/vr.151.8.243

2. Simpson SA, Syring R, Otto CM. Severe blunt trauma in dogs: 235 cases (1997-2003). J Vet Emerg Crit Care (San Antonio). (2009) 19:588602. doi: $10.1111 / \mathrm{j} .1476-4431.2009 .00468 . \mathrm{x}$

3. Platt SR, Radaelli ST, McDonnell JJ. The prognostic value of the modified Glasgow Coma Scale in head trauma in dogs. J Vet Intern Med. (2001) 15:581-4. doi: 10.1111/j.1939-1676.2001.tb01594.x

4. Sande A, West C. Traumatic brain injury: a review of pathophysiology and management. J Vet Emerg Crit Care (San Antonio). (2010) 20:17790. doi: $10.1111 /$ j.1476-4431.2010.00527.x

5. The blood-brain barrier in health and disease. Ann Neurol Bas, kaya MK, Rao AM, Dog?an A, Donaldson D, Dempsey RJ. The biphasic opening of the blood-brain barrier in the cortex and hippocampus in resuscitation (131). PNPH has also been evaluated in mouse models of TBI with hemorrhage (131-133), and compared with crystalloid and whole blood resuscitation (131). Mice resuscitated with PNPH required smaller volume fluid resuscitation and had higher mean arterial blood pressure that remained normal and stable through to the end of the experiment without the need for additional fluid infusion. In addition, they had a lower ICP and markedly less brain edema compared to those resuscitated with crystalloid or whole blood.

Dodecafluoropentane emulsion is an oxygen-carrying perfluorocarbon emulsion also under investigation for use in patients with TBI. In humans it has a short half-life $(90 \mathrm{~min})$ and is cleared via exhalation from the lungs (135). It is administered IV, travels to the lungs where it picks up oxygen, then to the tissues where it delivers oxygen. It has been evaluated in a rat model of TBI where brain tissue oxygen levels increased to $146 \%$ of the post-injury, pre-treatment level, with no effect on systemic blood pressure, heart rate, biochemical parameters, or blood gas measurements $(135,136)$. Further evaluation is needed before these therapies can be recommended in clinical practice.

\section{CONCLUSION}

There is a paucity of information covering treatment of TBI in dogs and cats, which is limited to experimental data in primarily pigs and rats, and clinical data collected from human studies. Response to treatment can be complicated by acute hemorrhage. The research and limited clinical studies examined do not provide sufficient evidence for a preferred fluid type, although it appears that infusion of LRS is less desirable than other isotonic crystalloids, and the use of plasma products during resuscitation may convey an improved outcome. To further the knowledge base on therapeutic interventions for TBI in dogs and cats, future clinical studies should focus on the effect of specific fluid prescriptions and osmotic agents on short- and long-term outcome.

\section{AUTHOR CONTRIBUTIONS}

Both authors contributed to the body of the paper, reference research, and editing.

after traumatic brain injury in rats. Neurosci Lett. (1997) 226: 3336. doi: 10.1016/S0304-3940(97)00239-5

6. Habgood MD, Bye N, Dziegielewska KM, Ek CJ, Lane MA, Potter $A$, et al. Changes in blood-brain barrier permeability to large and small molecules following traumatic brain injury in mice. Eur J Neurosci. (2007) 25:231-8. doi: 10.1111/j.1460-9568.2006. 05275.x

7. Rudloff E, Hopper K. Crystalloid and colloid compositions and their impact. Front Vet Sci. (2021). 8:639848. doi: 10.3389/fvets.2021.639848

8. Carney N, Totten AM, O'Reilly C, Ullman JS, Hawryluk GW, Bell MJ, et al. Guidelines for the Management of Severe Traumatic Brain Injury, Fourth Edition. Neurosurgery. (2017) 80:6-15. doi: 10.1227/NEU.0000000000001432

9. Grände PO. Critical Evaluation of the Lund Concept for Treatment of Severe Traumatic Head Injury, 25 Years after Its Introduction. Front Neurol. (2017) 8:315. doi: 10.3389/fneur.2017.00315 
10. Muzevic D, Splavski B. The Lund concept for severe traumatic brain injury. Cochrane Datab Syst Rev. (2013) CD010193. doi: 10.1002/14651858.CD010193.pub2

11. Caplan HW, Cox CS. Resuscitation Strategies for Traumatic Brain Injury. Curr Surg Rep. (2019) 7:14. doi: 10.1007/s40137-019-0237-x

12. Santry HP, Alam HB. Fluid resuscitation: past, present, and the future. Shock. (2010) 33:229-41. doi: 10.1097/SHK.0b013e3181c30f0c

13. Bickell WH, Wall MJ Jr, Pepe PE, Martin RR, Ginger VF, Allen MK. Immediate versus delayed fluid resuscitation for hypotensive patients with penetrating torso injuries. N Engl J Med. (1994) 331:110509. doi: 10.1056/NEJM199410273311701

14. Kwan I, Bunn F, Chinnock P, Roberts I. Timing and volume of fluid administration for patients with bleeding. Cochrane Database Syst Rev. (2014) CD002245. doi: 10.1002/14651858.CD002245.pub2

15. Leibner E, Andreae M, Galvagno SM, Scalea T. Damage control resuscitation. Clin Exp Emerg Med. (2020) 7:5-13. doi: 10.15441/ceem.19.089

16. Asgeirsson B, Grände PO, Nordström $\mathrm{CH}$, Messeter $\mathrm{K}$, Sjöholm $\mathrm{H}$. Cerebral haemodynamic effects of dihydroergotamine in patients with severe traumatic brain lesions. Acta Anaesthesiol Scand. (1995) 39:92230. doi: 10.1111/j.1399-6576.1995.tb04199.x

17. Dekker SE, Nikolian VC, Sillesen M, Bambakidis T, Schober P, Alam HB. Different resuscitation strategies and novel pharmacologic treatment with valproic acid in traumatic brain injury. J Neurosci Res. (2018) 96:71119. doi: $10.1002 /$ jnr. 24125

18. Vrettos T, Poimenidi E, Athanasopoulos P, Balasis S, Karagiorgos N, Siklis $\mathrm{T}$, et al. The effect of permissive hypotension in combined traumatic brain injury and blunt abdominal trauma: an experimental study in swines. Eur Rev Med Pharmacol Sci. (2016) 20:620-30.

19. Crookes BA, Cohn SM, Bonet H, Burton EA, Nelson J, Majetschak M, Varon AJ, Linden JM, Proctor KG. Building a better fluid for emergency resuscitation of traumatic brain injury. J Trauma. (2004) 57:54754. doi: 10.1097/01.TA.0000135162.85859.4C

20. King DR, Cohn SM, Proctor KG. Changes in intracranial pressure, coagulation, and neurologic outcome after resuscitation from experimental traumatic brain injury with hetastarch. Surgery. (2004) 136:355-63. doi: 10.1016/j.surg.2004.05.011

21. Hwabejire JO, Imam AM, Jin G, Liu B, Li Y, Sillesen M, et al. Differential effects of fresh frozen plasma and normal saline on secondary brain damage in a large animal model of polytrauma, hemorrhage and traumatic brain injury. J Trauma Acute Care Surg. (2013) 75:96874. doi: 10.1097/TA.0b013e31829a021a

22. Imam A, Jin G, Sillesen M, Dekker SE, Bambakidis T, Hwabejire JO, et al. Fresh frozen plasma resuscitation provides neuroprotection compared to normal saline in a large animal model of traumatic brain injury and polytrauma. J Neurotrauma. (2015) 32:307-13. doi: 10.1089/neu.2014.3535

23. Imam AM, Jin G, Sillesen M, Duggan M, Jepsen $\mathrm{CH}$, Hwabejire JO, et al. Early treatment with lyophilized plasma protects the brain in a large animal model of combined traumatic brain injury and hemorrhagic shock. J Trauma Acute Care Surg. (2013) 75:976-83. doi: 10.1097/TA.0b013e31829e2186

24. Jin G, DeMoya MA, Duggan M, Knightly T, Mejaddam AY, Hwabejire J, et al. Traumatic brain injury and hemorrhagic shock: evaluation of different resuscitation strategies in a large animal model of combined insults. Shock. (2012) 38:49-56. doi: 10.1097/SHK.0b013e3182574778

25. Imam AM, Jin G, Duggan M, Sillesen M, Hwabejire JO, Jepsen $\mathrm{CH}$, et al. Synergistic effects of fresh frozen plasma and valproic acid treatment in a combined model of traumatic brain injury and hemorrhagic shock. Surgery. (2013) 154:388-96. doi: 10.1016/j.surg.2013.05.008

26. Sillesen M, Bambakidis T, Dekker SE, Li Y, Alam HB. Fresh Frozen Plasma Modulates Brain Gene Expression in a Swine Model of Traumatic Brain Injury and Shock: A Network Analysis. J Am Coll Surg. (2017) 224:4958. doi: 10.1016/j.jamcollsurg.2016.09.015

27. Sillesen M, Jin G, Johansson PI, Alam HB. Resuscitation speed affects brain injury in a large animal model of traumatic brain injury and shock. Scand $J$ Trauma Resusc Emerg Med. (2014) 22:46. doi: 10.1186/s13049-014-0046-2

28. Georgoff PE, Nikolian VC, Halaweish I, Chtraklin K, Bruhn PJ, Eidy H, et al. Resuscitation with Lyophilized Plasma Is Safe and Improves Neurological Recovery in a Long-Term Survival Model of Swine Subjected to Traumatic
Brain Injury, Hemorrhagic Shock, and Polytrauma. J Neurotrauma. (2017) 34:2167-2175. doi: 10.1089/neu.2016.4859

29. Myburgh JA. Fluid resuscitation in acute medicine: what is the current situation? J Intern Med. (2015) 277:58-68. doi: 10.1111/joim.12326

30. Drummond JC, Patel PM, Cole DJ, Kelly PJ. The effect of the reduction of colloid oncotic pressure, with and without reduction of osmolality, on post-traumatic cerebral edema. Anesthesiology. (1998) 88:9931002. doi: 10.1097/00000542-199804000-00020

31. Sekhon MS, Dhingra VK, Sekhon IS, Henderson WR, McLean N, Griesdale DE. The safety of synthetic colloid in critically ill patients with severe traumatic brain injuries. J Crit Care. (2011) 26:35762. doi: $10.1016 /$ j.jcrc.2010.12.001

32. Myburgh JA, Finfer S, Bellomo R, Billot L, Cass A, Gattas D, Glass $\mathrm{P}$, et al. Hydroxyethyl starch or saline for fluid resuscitation in intensive care. N Engl J Med. (2012) 367:1901-11. doi: 10.1056/NEJMoa12 09759

33. Gantner D, Moore EM, Cooper DJ. Intravenous fluids in traumatic brain injury: what's the solution? Curr Opin Crit Care. (2014) 20:3859. doi: 10.1097/MCC.0000000000000114

34. SAFE Study Investigators, Australian and New Zealand Intensive Care Society Clinical Trials Group, Australian Red Cross Blood Service, George Institute for International Health, Myburgh J, Cooper DJ, et al. Saline or albumin for fluid resuscitation in patients with traumatic brain injury. $N$ Engl J Med. (2007) 357:874-84. doi: 10.1056/NEJMoa067514

35. Finfer S, Bellomo R, Boyce N, French J, Myburgh J, Norton R. SAFE Study Investigators. A comparison of albumin and saline for fluid resuscitation in the intensive care unit. N Engl J Med. (2004) 350:2247-56. doi: 10.1056/NEJMoa040232

36. Van Aken HK, Kampmeier TG, Ertmer C, Westphal M. Fluid resuscitation in patients with traumatic brain injury: what is a SAFE approach? Curr Opin Anaesthesiol. (2012) 25:563-5. doi: 10.1097/ACO.0b013e3283572274

37. Belayev L, Alonso OF, Huh PW, Zhao W, Busto R, Ginsberg MD. Posttreatment with high-dose albumin reduces histopathological damage and improves neurological deficit following fluid percussion brain injury in rats. J Neurotrauma. (1999) 16:445-53. doi: 10.1089/neu.1999.16.445

38. Tomita H, Ito U, Tone O, Masaoka $\mathrm{H}$, Tominaga B. High colloid oncotic therapy for contusional brain edema. Acta Neurochir Suppl (Wien). (1994) 60:547-9. doi: 10.1007/978-3-7091-9334-1_151

39. Chang R, Folkerson LE, Sloan D, Tomasek JS, Kitagawa RS, Choi HA, et al. Early plasma transfusion is associated with improved survival after isolated traumatic brain injury in patients with multifocal intracranial hemorrhage. Surgery. (2017) 161:538-545. doi: 10.1016/j.surg.2016.08.023

40. Kasotakis G, Sideris A, Yang Y, de Moya M, Alam H, King DR, Tompkins R, Velmahos G; Inflammation and Host Response to Injury Investigators. Aggressive early crystalloid resuscitation adversely affects outcomes in adult blunt trauma patients: an analysis of the Glue Grant database. J Trauma Acute Care Surg. (2013) 74:1215-21. doi: 10.1097/01586154-201305000-00005

41. Kozar RA, Peng Z, Zhang R, Holcomb JB, Pati S, Park P, et al. Plasma restoration of endothelial glycocalyx in a rodent model of hemorrhagic shock. Anesth Analg. (2011) 112:128995. doi: 10.1213/ANE.0b013e318210385c

42. Nikolian VC, Dekker SE, Bambakidis T, Higgins GA, Dennahy IS, Georgoff PE, et al. Improvement of Blood-Brain Barrier Integrity in Traumatic Brain Injury and Hemorrhagic Shock Following Treatment With Valproic Acid and Fresh Frozen Plasma. Crit Care Med. (2018) 46:e5966. doi: 10.1097/CCM.0000000000002800

43. McDaniel S, Golla S, Moore AN, DaCorta J, Bode A, Pati S, Dash PK, Zhao J. Resuscitation of Hypotensive Traumatic Brain Injured Animals With Spray-Dried Plasma Does Not Adversely Alter Physiology and Improves Blood-Brain Barrier Function. Mil Med. (2017) 182:e170611. doi: 10.7205/MILMED-D-16-00185

44. Halaweish I, Bambakidis T, Nikolian VC, Georgoff P, Bruhn P, Piascik P, et al. Early resuscitation with lyophilized plasma provides equal neuroprotection compared with fresh frozen plasma in a large animal survival model of traumatic brain injury and hemorrhagic shock. J Trauma Acute Care Surg. (2016) 81:1080-7. doi: 10.1097/TA.0000000000001204 
45. Bailey ZS, Leung LY, Yang X, Cardiff K, Gilsdorf J, Shear D, Kochanek PM. Prehospital Whole Blood Resuscitation Reduces Fluid Requirement While Maintaining Critical Physiology in a Model of Penetrating Traumatic Brain Injury and Hemorrhage: Implications on Resource-Limited Combat Casualty Care. Shock. (2021) 55:545-53. doi: 10.1097/SHK.0000000000001662

46. Gruen DS, Guyette FX, Brown JB, Okonkwo DO, Puccio AM, Campwala IK, et al. Association of Prehospital Plasma With Survival in Patients With Traumatic Brain Injury: A Secondary Analysis of the PAMPer Cluster Randomized Clinical Trial. JAMA Netw Open. (2020) 3:e2016869. doi: 10.1001/jamanetworkopen.2020.16869

47. Halaweish I, Bambakidis T, He W, Linzel D, Chang Z, Srinivasan A, et al. Early resuscitation with fresh frozen plasma for traumatic brain injury combined with hemorrhagic shock improves neurologic recovery. J Am Coll Surg. (2015) 220:809-19. doi: 10.1016/j.jamcollsurg.2015.01.057

48. Hernandez MC, Thiels CA, Aho JM, Habermann EB, Zielinski MD, Stubbs JA, et al. Prehospital plasma resuscitation associated with improved neurologic outcomes after traumatic brain injury. J Trauma Acute Care Surg. (2017) 83:398-405. doi: 10.1097/TA.0000000000001581

49. Leibowitz A, Brotfain E, Koyfman L, Klein M, Hess S, Zlotnik A, et al. Treatment of combined traumatic brain injury and hemorrhagic shock with fractionated blood products versus fresh whole blood in a rat model. Eur J Trauma Emerg Surg. (2019) 45:26-71. doi: 10.1007/s00068-018-0908-9

50. Zhang LM, Li R, Sun WB, Wang XP, Qi MM, Bai Y, et al. Low-Dose, Early Fresh Frozen Plasma Transfusion Therapy After Severe Trauma Brain Injury: A Clinical, Prospective, Randomized, Controlled Study. World Neurosurg. (2019) 132:e21-27. doi: 10.1016/j.wneu.2019.09.024

51. Etemadrezaie H, Baharvahdat H, Shariati Z, Lari SM, Shakeri MT, Ganjeifar B. The effect of fresh frozen plasma in severe closed head injury. Clin Neurol Neurosurg. (2007) 109:166-71. doi: 10.1016/j.clineuro.2006.09.001

52. Sperry JL, Guyette FX, Brown JB, Yazer MH, Triulzi DJ, Early-Young BJ, et al. Prehospital Plasma during Air Medical Transport in Trauma Patients at Risk for Hemorrhagic Shock. N Engl J Med. (2018) 379:31526. doi: 10.1056/NEJMoa1802345

53. Jokar TO, Khalil M, Rhee P, Kulvatunyou N, Pandit V, O'Keeffe T, et al. Ratio-based Resuscitation in Trauma Patients with Traumatic Brain Injury: Is There a Similar Effect? Am Surg. (2016) 82:2717. doi: 10.1177/000313481608200322

54. Zornow MH, Oh YS, Scheller MS. A comparison of the cerebral and haemodynamic effects of mannitol and hypertonic saline in an animal model of brain injury. Acta Neurochir Suppl (Wien). (1990) 51:3245. doi: 10.1007/978-3-7091-9115-6_109

55. Marshall LF, SMith RW, Rauscher LA, Shapiro HM. Mannitol dose requirements in brain-injured patients. J Neurosurg. (1978) 48:16972. doi: 10.3171/jns.1978.48.2.0169

56. Barry KG, Berman AR. Mannitol infusion. III. The acute effect of the intravenous infusion of mannitol on blood and plasma volumes. $N$ Engl J Med. (1961) 264:1085-8. doi: 10.1056/NEJM196105252642105

57. McGraw CP, Howard G. Effect of mannitol on increased intracranial pressure. Neurosurgery. (1983) 13:26971. doi: 10.1227/00006123-198309000-00009

58. Zornow MH. Hypertonic saline as a safe and efficacious treatment of intracranial hypertension. J Neurosurg Anesthesiol. (1996) 8:1757. doi: 10.1097/00008506-199604000-00021

59. Berger S, Schürer L, Härtl R, Messmer K, Baethmann A. Reduction of post-traumatic intracranial hypertension by hypertonic/hyperoncotic saline/dextran and hypertonic mannitol. Neurosurgery. (1995) 37:98107. doi: 10.1227/00006123-199507000-00015

60. Bulger EM, May S, Brasel KJ, Schreiber M, Kerby JD, Tisherman SA, et al. Out-of-hospital hypertonic resuscitation following severe traumatic brain injury: a randomized controlled trial. JAMA. (2010) 304:145564. doi: 10.1001/jama.2010.1405

61. Cooper DJ, Myles PS, McDermott FT, Murray LJ, Laidlaw J, Cooper G, et al. Prehospital hypertonic saline resuscitation of patients with hypotension and severe traumatic brain injury: a randomized controlled trial. JAMA. (2004) 29:1350-7. doi: 10.1001/jama.291.11.1350

62. Rickard AC, Smith JE, Newell P, Bailey A, Kehoe A, Mann C. Salt or sugar for your injured brain? A meta-analysis of randomised controlled trials of mannitol versus hypertonic sodium solutions to manage raised intracranial pressure in traumatic brain injury. Emerg Med J. (2014 31:67983. doi: 10.1136/emermed-2013-202679

63. Pinto FC, Capone-Neto A, Prist R, E Silva MR, Poli-de-Figueiredo LF. Volume replacement with lactated Ringer's or 3\% hypertonic saline solution during combined experimental hemorrhagic shock and traumatic brain injury. J Trauma. (2006) 60:758-63. doi: 10.1097/01.ta.0000214581.89316.73

64. Pinto FC, Oliveira MF, Prist R, Silva MR, Silva LF, Capone Neto A. Effect of volume replacement during combined experimental hemorrhagic shock and traumatic brain injury in prostanoids, brain pathology and pupil status. Arq Neuropsiquiatr. (2015) 73:499-505. doi: 10.1590/0004-282X20150039

65. Sell SL, Avila MA, Yu G, Vergara L, Prough DS, Grady JJ, et al. Hypertonic resuscitation improves neuronal and behavioral outcomes after traumatic brain injury plus hemorrhage. Anesthesiology. (2008) 108:87381. doi: 10.1097/ALN.0b013e31816c8a15

66. Dickson JM, Wang X, St John AE, Lim EB, Stern SA, White NJ. Damage Control Resuscitation Supplemented with Vasopressin in a Severe Polytrauma Model with Traumatic Brain Injury and Uncontrolled Internal Hemorrhage. Mil Med. (2018) 183:e460-66. doi: 10.1093/milmed/usy001

67. Chatrath V, Khetarpal R, Ahuja J. Fluid management in patients with trauma: Restrictive versus liberal approach. J Anaesthesiol Clin Pharmacol. (2015) 31:308-16. doi: 10.4103/0970-9185.161664

68. Chesnut RM, Marshall SB, Piek J, Blunt BA, Klauber MR, Marshall LF. Early and late systemic hypotension as a frequent and fundamental source of cerebral ischemia following severe brain injury in the Traumatic Coma Data Bank. Acta Neurochir Suppl (Wien). (1993) 59:121-125. doi: 10.1007/978-3-7091-9302-0_21

69. Bratton SL, Chestnut RM, Ghajar J, Hammound F, Harris O, Hartl R, et al. Guidelines for the management of severe traumatic brain injury. II. Hyperosmolar therapy. J Neurotrauma. (2007) 24:S14-20. doi: 10.1089/neu.2007.9994

70. Muizelaar JP, Wei EP, Kontos HA, Becker DP. Mannitol causes compensatory cerebral vasoconstriction and vasodilation in response to blood viscosity changes. J Neurosurg. (1983) 59:822-828. doi: 10.3171/jns.1983.59.5.0822

71. Ballocco I, Evangelisti MA, Deiana R, Cubeddu F, Pinna Parpaglia ML, Serra $\mathrm{G}$, et al. A pilot study evaluating the effect of mannitol and hypertonic saline solution in the treatment of increased intracranial pressure in 2 cats and 1 dog naturally affected by traumatic brain injury. J Vet Emerg Crit Care (San Antonio). (2019) 29:578-84. doi: 10.1111/vec.12880

72. Major EH, O'Connor P, Mullan B. Single bolus $30 \%$ hypertonic saline for refractory intracranial hypertension. Ir J Med Sci. (2015) 184:15965. doi: 10.1007/s11845-014-1080-9

73. Mortazavi MM, Romeo AK, Deep A, Griessenauer CJ, Shoja MM, Tubbs RS, Fisher W. Hypertonic saline for treating raised intracranial pressure: literature review with meta-analysis. J Neurosurg. (2012) 116:21021. doi: 10.3171/2011.7.JNS102142

74. Kamel H, Navi BB, Nakagawa K, Hemphill JC 3rd, Ko NU. Hypertonic saline versus mannitol for the treatment of elevated intracranial pressure: a meta-analysis of randomized clinical trials. Crit Care Med. (2011) 39:5549. doi: 10.1097/CCM.0b013e318206b9be

75. Burgess S, Abu-Laban RB, Slavik RS, Vu EN, Zed PJ. A Systematic Review of Randomized Controlled Trials Comparing Hypertonic Sodium Solutions and Mannitol for Traumatic Brain Injury: Implications for Emergency Department Management. Ann Pharmacother. (2016) 50:291300doi: 10.1177/1060028016628893

76. Chen H, Song Z, Dennis JA. Hypertonic saline versus other intracranial pressure-lowering agents for people with acute traumatic brain injury. Cochrane Datab Syst Rev. (2020) CD010904. doi: 10.1002/14651858.CD010904.pub3

77. Fenn NE 3rd, Sierra CM. Hyperosmolar Therapy for Severe Traumatic Brain Injury in Pediatrics: A Review of the Literature. J Pediatr Pharmacol Ther. (2019) 24:465-72. doi: 10.5863/1551-6776-24.6.465

78. Wakai A, McCabe A, Roberts I, Schierhout G. Mannitol for acute traumatic brain injury. Cochrane Database Syst Rev. (2013) CD001049. doi: 10.1002/14651858.CD001049.pub5

79. Worthley LI, Cooper DJ, Jones N. Treatment of resistant intracranial hypertension with hypertonic saline. Report of two cases. J Neurosurg. (1988) 68:478-81. doi: 10.3171/jns.1988.68.3.0478 
80. Gu J, Huang H, Huang Y, Sun H, Xu H. Hypertonic saline or mannitol for treating elevated intracranial pressure in traumatic brain injury: a meta-analysis of randomized controlled trials. Neurosurg Rev. (2019) 42:499509. doi: 10.1007/s10143-018-0991-8

81. Miyoshi Y, Kondo Y, Suzuki H, Fukuda T, Yasuda H, Yokobori S; Japan Resuscitation Council (JRC) Neuroresuscitation Task Force and the Guidelines Editorial Committee. Effects of hypertonic saline versus mannitol in patients with traumatic brain injury in prehospital, emergency department, and intensive care unit settings: a systematic review and metaanalysis. J Intensive Care. (2020) 8:61. doi: 10.1186/s40560-020-00476-x

82. Poole D, Citerio G, Helbok R, Ichai C, Meyfroidt G, Oddo M, Payen JF, Stocchetti N. Evidence for Mannitol as an Effective Agent Against Intracranial Hypertension: An Individual Patient Data Metaanalysis. Neurocrit Care. (2020) 32:252-61. doi: 10.1007/s12028-01900771-y

83. Shi J, Tan L, Ye J, Hu L. Hypertonic saline and mannitol in patients with traumatic brain injury: A systematic and meta-analysis. Medicine (Baltimore). (2020) 99(35):e21655. doi: 10.1097/MD.00000000000 21655

84. Huang X, Yang L, Ye J, He S, Wang B. Equimolar doses of hypertonic agents (saline or mannitol) in the treatment of intracranial hypertension after severe traumatic brain injury. Medicine (Baltimore). (2020) 99:e22004. doi: 10.1097/MD.0000000000022004

85. García-Sola R, Pulido P, Capilla P. The immediate and long-term effects of mannitol and glycerol. A comparative experimental study. Acta Neurochir (Wien). (1991) 10:114-21. PMID: 1907077. doi: 10.1007/BF01403005

86. Kotwica Z, Persson L. Effect of mannitol on intracranial pressure in focal cerebral ischemia. An experimental study in a rat. Mater Med Pol. (1991) 23:280-4.

87. McManus ML, Soriano SG. Rebound swelling of astroglial cells exposed to hypertonic mannitol. Anesthesiology. (1998) 88:1586-91. doi: 10.1097/00000542-199806000-00023

88. Palma L, Bruni G, Fiaschi AI, Mariottini A. Passage of mannitol into the brain around gliomas: a potential cause of rebound phenomenon. A study on 21 patients. J Neurosurg Sci. (2006) 50:63-6.

89. Sankar T, Assina R, Karis JP, Theodore N, Preul MC. Neurosurgical implications of mannitol accumulation within a meningioma and its peritumoral region demonstrated by magnetic resonance spectroscopy: case report. J Neurosurg. (2008) 108:1010-3. doi: 10.3171/JNS/2008/108/5/1010

90. Cruz J, Minoja G, Okuchi K. Improving clinical outcomes from acute subdural hematomas with the emergency preoperative administration of high doses of mannitol: a randomized trial. Neurosurgery. (2001) 49:864871. doi: 10.1227/00006123-200110000-00016

91. Cruz J, Minoja G, Okuchi K. Major clinical and physiological benefits of early high doses of mannitol for intraparenchymal temporal lobe hemorrhages with abnormal pupillary widening: a randomized trial. Neurosurgery. (2002) 51:628-37. doi: 10.1097/00006123-200209000-00006

92. Cruz J, Minoja G, Okuchi K, Facco E. Successful use of the new highdose mannitol treatment in patients with Glasgow Coma Scale scores of 3 and bilateral abnormal pupillary widening: a randomized trial. J Neurosurg. (2004) 100:376-83. doi: 10.3171/jns.2004.100.3.0376

93. Sorani MD, Manley GT. Dose-response relationship of mannitol and intracranial pressure: a metaanalysis. J Neurosurg. (2008) 108:80-7. doi: 10.3171/JNS/2008/108/01/0080

94. Cook AM, Morgan Jones G, Hawryluk GWJ, Mailloux P, McLaughlin D, Papangelou A, et al. Guidelines for the Acute Treatment of Cerebral Edema in Neurocritical Care Patients. Neurocrit Care. (2020) 32:64766. doi: 10.1007/s12028-020-00959-7

95. Asehnoune K, Lasocki S, Seguin P, Geeraerts T, Perrigault PF, DahyotFizelier C, et al. Association between continuous hyperosmolar therapy and survival in patients with traumatic brain injury - a multicentre prospective cohort study and systematic review. Crit Care. (2017) 21:328. doi: 10.1186/s13054-017-1918-4

96. Qureshi AI, Suarez JI, Bhardwaj A, Mirski M, Schnitzer MS, Hanley DF, Ulatowski JA. Use of hypertonic (3\%) saline/acetate infusion in the treatment of cerebral edema: Effect on intracranial pressure and lateral displacement of the brain. Crit Care Med. (1998) 26:4406. doi: 10.1097/00003246-199803000-00011
97. Mangat HS. Hypertonic saline infusion for treating intracranial hypertension after severe traumatic brain injury. Crit Care. (2018) 22:37. doi: 10.1186/s13054-018-1963-7

98. Gonda DD, Meltzer HS, Crawford JR, Hilfiker ML, Shellington DK, Peterson $\mathrm{BM}$, et al. Complications associated with prolonged hypertonic saline therapy in children with elevated intracranial pressure. Pediatr Crit Care Med. (2013) 14:610-20. doi: 10.1097/PCC.0b013e318291772b

99. Froelich M, Ni Q, Wess C, Ougorets I, Härtl R. Continuous hypertonic saline therapy and the occurrence of complications in neurocritically ill patients. Crit Care Med. (2009) 37:1433-41. doi: 10.1097/CCM.0b013e31819c1933

100. Vedantam A, Robertson CS, Gopinath SP. Morbidity and mortality associated with hypernatremia in patients with severe traumatic brain injury. Neurosurg Focus. (2017) 43:E2. doi: 10.3171/2017.7.FOCUS17418

101. Tan SK, Kolmodin L, Sekhon MS, Qiao L, Zou J, Henderson WR, Griesdale DE. The effect of continuous hypertonic saline infusion and hypernatremia on mortality in patients with severe traumatic brain injury: a retrospective cohort study. Can J Anaesth. (2016) 63:6647. doi: 10.1007/s12630-016-0633-y

102. Roquilly A, Moyer JD, Huet O, Lasocki S, Cohen B, Dahyot-Fizelier C, et al. Effect of Continuous Infusion of Hypertonic Saline vs Standard Care on 6-Month Neurological Outcomes in Patients With Traumatic Brain Injury: The COBI Randomized Clinical Trial. JAMA. (2021) 325:20562066. doi: 10.1001/jama.2021.5561

103. Wei EP, Dietrich WD, Povlishock JT, Navari RM, Kontos HA. Functional, morphological, and metabolic abnormalities of the cerebral microcirculation after concussive brain injury in cats. Circ Res. (1980) 46:376-47. doi: 10.1161/01.RES.46.1.37

104. Coimbra R, Junger WG, Hoyt DB, Liu FC, Loomis WH, Evers MF. Hypertonic saline resuscitation restores hemorrhage-induced immunosuppression by decreasing prostaglandin E2 and interleukin-4 production. J Surg Res. (1996) 64:203-9. doi: 10.1006/jsre.1996.0329

105. Coimbra R, Junger WG, Liu FC, Loomis WH, Hoyt DB. Hypertonic/hyperoncotic fluids reverse prostaglandin E2 (PGE2)-induced T-cell suppression. Shock. (1995) 4:45-9. doi: 10.1097/00024382-199507000-00007

106. Junger WG, Hoyt DB, Hamreus M, Liu FC, Herdon-Remelius C, Junger W, Altman A. Hypertonic saline activates protein tyrosine kinases and mitogen-activated protein kinase p38 in T-cells. J Trauma. (1997) 42:43743. doi: 10.1097/00005373-199703000-00011

107. Junger WG, Liu FC, Loomis WH, Hoyt DB. Hypertonic saline enhances cellular immune function. Circ Shock. (1994) 42:190-6.

108. Koura SS, Doppenberg EM, Marmarou A, Choi S, Young HF, Bullock R. Relationship between excitatory amino acid release and outcome after severe human head injury. Acta Neurochir Suppl. (1998) 71:2446. doi: 10.1007/978-3-7091-6475-4 70

109. Nicholls D, Attwell D. The release and uptake of excitatory amino acids. Trends Pharmacol Sci. (1990) 11:462-8. doi: 10.1016/0165-6147(90)90129-V

110. Vespa P, Prins M, Ronne-Engstrom E, Caron M, Shalmon E, Hovda DA, et al. Increase in extracellular glutamate caused by reduced cerebral perfusion pressure and seizures after human traumatic brain injury: a microdialysis study. J Neurosurg. (1998) 89:971-82. doi: 10.3171/jns.1998.89.6.0971

111. Shackford SR, Fortlage DA, Peters RM, Hollingsworth-Fridlund P, Sise MJ. Serum osmolar and electrolyte changes associated with large infusions of hypertonic sodium lactate for intravascular volume expansion of patients undergoing aortic reconstruction. Surg Gynecol Obstet. (1987) 164:127-36.

112. Rabinovici R, Vernick J, Hillegas L, Neville LF. Hypertonic saline treatment of acid aspiration-induced lung injury. J Surg Res. (1996) 60:17680. doi: 10.1006/jsre.1996.0028

113. Read RC, Johnson JA, Vick JA, Meyer MW. Vascular effects of hypertonic solutions. Circ Res. (1960) 8:538-48. doi: 10.1161/01.RES.8.3.538

114. Shackford SR, Norton CH, Todd MM. Renal, cerebral, and pulmonary effects of hypertonic resuscitation in a porcine model of hemorrhagic shock. Surgery. (1988) 104:553-60. doi: 10.1097/00132586-198906000-00057

115. Shackford SR, Schmoker JD, Zhuang J. The effect of hypertonic resuscitation on pial arteriolar tone after brain injury and shock. J Trauma. (1994) 37:899-908. doi: 10.1097/00005373-199412000-00005

116. Shackford SR, Zhuang J, Schmoker J. Intravenous fluid tonicity: effect on intracranial pressure, cerebral blood flow, and cerebral 
oxygen delivery in focal brain injury. $J$ Neurosurg. (1992) 76:91-8. doi: 10.3171/jns.1992.76.1.0091

117. Mizoi K, Suzuki J, Imaizumi S, Yoshimoto T. Development of new cerebral protective agents: the free radical scavengers. Neurol Res. (1986) 8:7580. doi: $10.1080 / 01616412.1986 .11739734$

118. Coté CJ, Greenhow DE, Marshall BE. The hypotensive response to rapid intravenous administration of hypertonic solutions in man and in the rabbit. Anesthesiology. (1979) 50:30-5. doi: 10.1097/00000542-197901000-00007

119. Kien ND, Kramer GC, White DA. Acute hypotension caused by rapid hypertonic saline infusion in anesthetized dogs. Anesth Analg. (1991) 73:597-602. doi: 10.1213/00000539-199111000-00015

120. Agarwal JB, Baile EM, Palmer WH. Reflex systemic hypotension due to hypertonic solutions in pulmonary circulation. J Appl Physiol. (1969) 27:2515. doi: 10.1152/jappl.1969.27.2.251

121. Dobson GP, Letson HL. Adenosine, lidocaine, and $\mathrm{Mg} 2+$ (ALM): From cardiac surgery to combat casualty care-Teaching old drugs new tricks. J Trauma Acute Care Surg. (2016) 80:135-45. doi: 10.1097/TA.0000000000000881

122. Granfeldt A, Letson HL, Hyldebrandt JA, Wang ER, Salcedo PA, Nielsen TK, Tønnesen E, Vinten-Johansen J, Dobson GP. Small-volume 7.5\% $\mathrm{NaCl}$ adenosine, lidocaine, and $\mathrm{Mg} 2+$ has multiple benefits during hypotensive and blood resuscitation in the pig following severe blood loss: rat to pig translation. Crit Care Med. (2014) 42:e32944. doi: 10.1097/CCM.0000000000000225

123. Granfeldt A, Letson HL, Dobson GP, Shi W, Vinten-Johansen J, Tønnesen E. Adenosine, lidocaine and $\mathrm{Mg} 2+$ improves cardiac and pulmonary function, induces reversible hypotension and exerts antiinflammatory effects in an endotoxemic porcine model. Crit Care. (2014) 18:682. doi: 10.1186/s13054-014-0682-y

124. Griffin MJ, Letson HL, Dobson GP. Small-Volume Adenosine, Lidocaine, and $\mathrm{Mg} 2+4$-Hour Infusion Leads to $88 \%$ Survival after 6 Days of Experimental Sepsis in the Rat without Antibiotics. Clin Vaccine Immunol. (2016) 23:863-872. doi: 10.1128/CVI.00390-16

125. Letson HL, Dobson GP. $3 \% \mathrm{NaCl}$ adenosine, lidocaine, Mg2+ (ALM) bolus and 4 hours "drip" infusion reduces noncompressible hemorrhage by $60 \%$ in a rat model. J Trauma Acute Care Surg. (2017) 82:106372. doi: 10.1097/TA.0000000000001454

126. Letson H, Dobson G. Adenosine, lidocaine and Mg2+ (ALM) fluid therapy attenuates systemic inflammation, platelet dysfunction and coagulopathy after non-compressible truncal hemorrhage. PLoS ONE. (2017) 12:e0188144. doi: 10.1371/journal.pone. 0188144

127. Letson HL, Granfeldt A, Jensen TH, Mattson TH, Dobson GP. Adenosine, Lidocaine, and Magnesium Support a High Flow, Hypotensive, Vasodilatory State With Improved Oxygen Delivery and Cerebral Protection in a Pig Model of Noncompressible Hemorrhage. J Surg Res. (2020) 253:12738. doi: 10.1016/j.jss.2020.03.048

128. Letson HL, Dobson GP. Adenosine, lidocaine, and $\mathrm{Mg} 2+$ (ALM) resuscitation fluid protects against experimental traumatic brain injury. J Trauma Acute Care Surg. (2018) 84:908-916. doi: 10.1097/TA.0000000000001874
129. Temkin NR, Anderson GD, Winn HR, Ellenbogen RG, Britz GW, Schuster J, Lucas T, Newell DW, Mansfield PN, Machamer JE, Barber J, Dikmen SS. Magnesium sulfate for neuroprotection after traumatic brain injury: a randomised controlled trial. Lancet Neurol. (2007) 6:2938. doi: 10.1016/S1474-4422(06)70630-5

130. Bragin DE, Lara DA, Bragina OA, Kameneva MV, Nemoto EM. Resuscitation Fluid with Drag Reducing Polymer Enhances Cerebral Microcirculation and Tissue Oxygenation After Traumatic Brain Injury Complicated by Hemorrhagic Shock. Adv Exp Med Biol. (2018);1072:3943. doi: 10.1007/978-3-319-91287-5_7

131. Brockman EC, Jackson TC, Dixon CE, Bay?r H, Clark RS, Vagni V, Feldman K, Byrd C, Ma L, Hsia C, Kochanek PM. Polynitroxylated Pegylated Hemoglobin-A Novel, Small Volume Therapeutic for Traumatic Brain Injury Resuscitation: Comparison to Whole Blood and Dose Response Evaluation. J Neurotrauma. (2017) 34:1337-50. doi: 10.1089/neu.20 16.4656

132. Brockman EC, Bayir H, Blasiole B, Shein SL, Fink EL, Dixon C, Clark RS, Vagni VA, Ma L, Hsia CJ, Tisherman SA, Kochanek PM. Polynitroxylatedpegylated hemoglobin attenuates fluid requirements and brain edema in combined traumatic brain injury plus hemorrhagic shock in mice. J Cereb Blood Flow Metab. (2013) 33:1457-64. doi: 10.1038/jcbfm.20 13.104

133. Shellington DK, Du L, Wu X, Exo J, Vagni V, Ma L, Janesko-Feldman K, Clark RS, Bayir H, Dixon CE, Jenkins LW, Hsia CJ, Kochanek PM. Polynitroxylated pegylated hemoglobin: a novel neuroprotective hemoglobin for acute volume-limited fluid resuscitation after combined traumatic brain injury and hemorrhagic hypotension in mice. Crit Care Med. (2011) 39:494-505. PMID: 21169820; PMCID: PMC3425360. doi: 10.1097/CCM.0b013e318206blfa

134. Hsia CJ, Ma L. A hemoglobin-based multifunctional therapeutic: polynitroxylated pegylated hemoglobin. Artif Organs. (2012) 36:215-20. doi: 10.1111/j.1525-1594.2011.01307.x

135. Graham K, Moon-Massat PF, Unger EC. Dodecafluoropentane Emulsion (DDFPE) as a Resuscitation Fluid for Treatment of Hemorrhagic Shock and Traumatic Brain Injury: A Review. Shock. (2019) 52:5054. doi: 10.1097/SHK.0000000000001060

136. Mullah SH, Saha BK, Abutarboush R, Walker PB, Haque A, Arnaud FG, Hazzard B, Auker CR, McCarron RM, Scultetus AH, MoonMassat P. Perfluorocarbon NVX-108 increased cerebral oxygen tension after traumatic brain injury in rats. Brain Res. (2016) 1634:13239. doi: 10.1016/j.brainres.2016.01.012

Conflict of Interest: The authors declare that the research was conducted in the absence of any commercial or financial relationships that could be construed as a potential conflict of interest.

Copyright (C) 2021 Pigott and Rudloff. This is an open-access article distributed under the terms of the Creative Commons Attribution License (CC BY). The use, distribution or reproduction in other forums is permitted, provided the original author(s) and the copyright owner(s) are credited and that the original publication in this journal is cited, in accordance with accepted academic practice. No use, distribution or reproduction is permitted which does not comply with these terms. 